\title{
The Baller-Gerold syndrome
}

\author{
L Van Maldergem, A Verloes, L Lejeune, Y Gillerot
}

\begin{abstract}
A case of severe craniosynostosis-radial aplasia (Baller-Gerold) syndrome is described in a newborn male, following a pregnancy complicated by polyhydramnios and intrauterine growth retardation. Death occurred after two hours owing to a prolonged apnoeic spell. Extensive agenesis of the frontal and parietal bones, resulting in a very large fontanelle, in addition to coronal bilateral craniosynostosis was observed at necropsy. There was also bilateral radial agenesis, oligodactyly of the hands and feet, a midline facial angioma, and a scrotally positioned anus, all of which have been described in some of the 10 previously reported cases. Microcephaly, erythroblastosis of the liver, and pancreatic islet cell hypertrophy were also noted.
\end{abstract}

Syndromes with the association of craniosynostosis and multiple congenital abnormalities are numerous. There are also more than 50 syndromes including radial agenesis. However, there is only one rare syndrome with the association of craniosynostosis and radial agenesis, namely the Baller-Gerold syndrome. We present here a new case of this unusual syndrome.

\section{Case report}

The parents were Caucasian, aged 24 and 22 years, and were probably related since their

Received 17 December 1990. Revised version accepted 23 August 1991 grandmothers, bearing the same name, originated from the same small village and called each other 'cousin'. The pregnancy was uneventful until 7 months of gestation when intrauterine growth retardation (IUGR) was first detected on echography. Fetal weight calculated from abdominal measurement and femur length decreased from the 50th to the 3 rd centile. At 8 months, major malformations of the cranial vault could be seen. The limbs could not be visualised clearly because of the lack of amniotic fluid owing to advanced gestational age. Diabetes mellitus screening tests were negative. Birth occurred at 37 weeks with breech presentation. The baby weighed $2250 \mathrm{~g}$, length $43 \mathrm{~cm}$, and head circumference $35 \mathrm{~cm}$. Apgar score were 10 and 7 at one and five minutes. A severe malformation complex was obvious and included the following: turricephaly, short neck, shortening of the upper limbs, club hands and feet, and oligodactyly (fig 1). The baby became rapidly hypotonic, then cyanotic, and died despite attempts at resuscitation. Necropsy was performed four hours after death. The facial appearance was striking because of marked turricephaly, a large forehead, midfacial hypoplasia with a small nose covered by a midline angioma, anteverted nostrils, long upper lip where the angioma expanded, a very small mouth with a thin vermilion border, high arched palate without cleft, and slight retrognathia (fig 2). The ears were low set and posteriorly rotated. There was a partial agenesis of the cranial vault with the fontanelle wide open from the occiput to the supraorbital ridges (fig 3). Moderate micropolygyria of the deformed brain was noted. The neck was short and the nipples widely spaced. There was clinically evident bilateral radial agenesis and absence of the thumbs with shortening of the distal and middle phalanges. The anus was anteriorly placed at the posterior limit of the scrotum (fig 4). No cardiac abnormality was found. Microscopically, there was a slight overdevelopment of the endocrine pancreas. Otherwise, histological examination of all other organs was unremarkable. Karyotype was $46, \mathrm{XY}$ (G and $\mathrm{R}$ banding) on peripheral lymphocytes and cultured skin fibroblasts.

\section{Discussion}

The Baller-Gerold syndrome, an autosomal recessive craniosynostosis complex associated with agenesis or severe hypoplasia of the radius, has been previously described 12 times. ${ }^{1-10}$ The phenotype has been outlined in a recent review by Cohen ${ }^{11}$ and includes growth deficiency, sudden infant death syndrome (neonatal death occurred in our case), a peculiar facial appearance with malformed (5/11)
Figure 1 General appearance of the proband (left) and his skeletal abnormalities (right). The limits of the anterior fontanelle are drawn. Note the short neck, club hands, phocomelia, oligodactyly, small, bowed ulnae, and absent radii. 


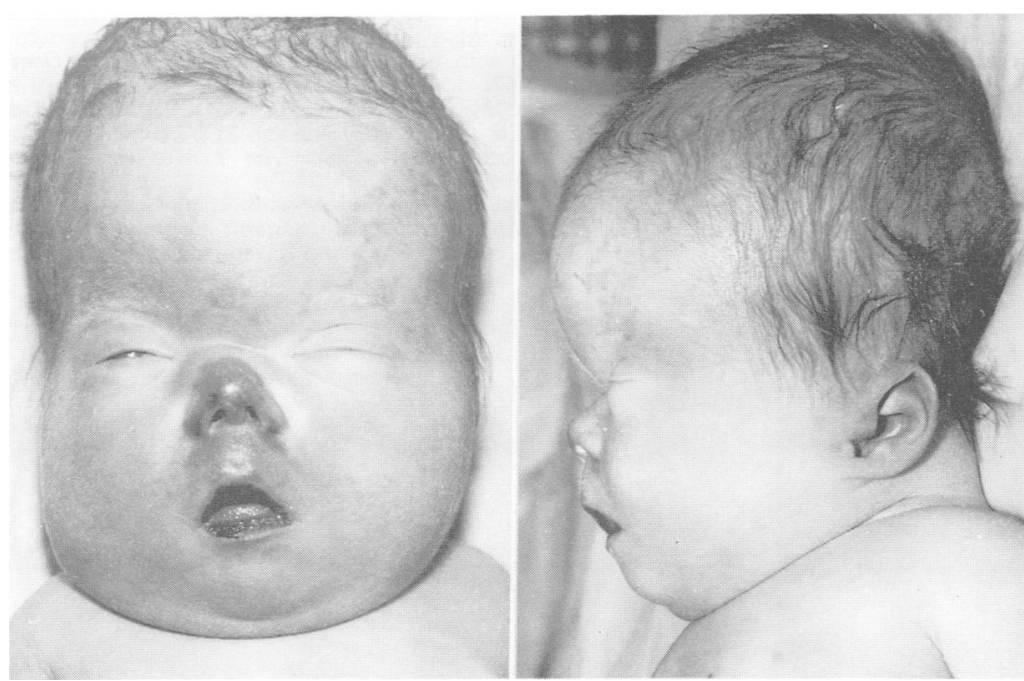

Figure 2 Facial characteristics reminiscent of Apert acrocephalosyndactyly: prominent forehead, angulated nasal root, small, upturned saddle nose, telecanthus, and, in addition, more specific signs including nasal haemangiomata plana, small, downturned mouth with thin vermilion border, blunt, long philtrum, and apparently very low set, posteriorly rotated ears and attached lobes. Note also the abundant posterior subcutaneous fat of the short neck in profile.

and low set $(2 / 11)$ ears, prominent nasal bridge (3/11), epicanthus $(3 / 11)$, a midline capillary haemangioma (3/9), and micrognathia $(2 / 12)$, all of which were present in our case apart from epicanthus. Other occasionally (3/12) described facial features (cleft palate, bifid uvula, high arched palate, and prominent mandible) were absent. Other systems involved are cardiac (VSD, patent ductus arteriosus, supravalvular aortic stenosis), renal (ectopia), anal (imperforate anus, anterior position, perineal fistula), and skeletal (joint limitations, rib fusion and flat vertebrae, absent middle phalanx). It is worth noting that cardiac malformations were absent in our patient but the midline angioma and the anteriorly displaced anus were present. In addition, together with severe craniosynostosis, a lack of coalescence
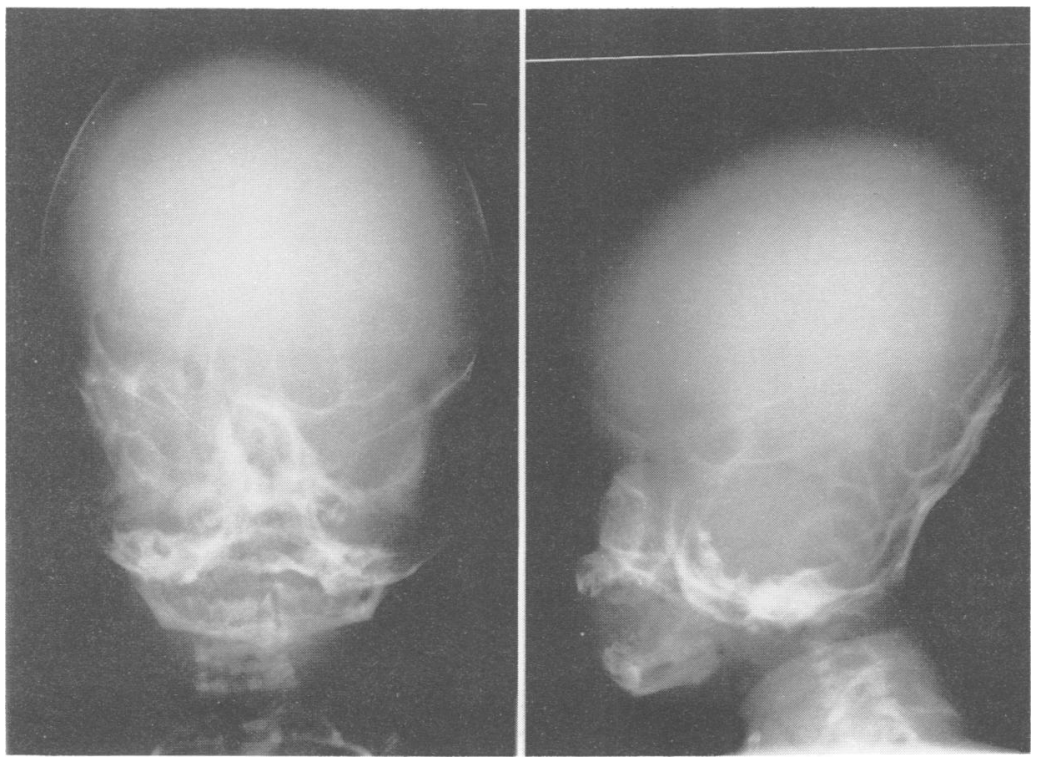

Figure 3 Incomplete formation of the cranial vault cannot be seen on the radiographs. However, brachyturricephaly and midfacial hypoplasia are evident, pointing to craniosynostosis. The coronal sutures appear open and a lacunar appearance

('Lückenschadl') is noted in occipital regions.

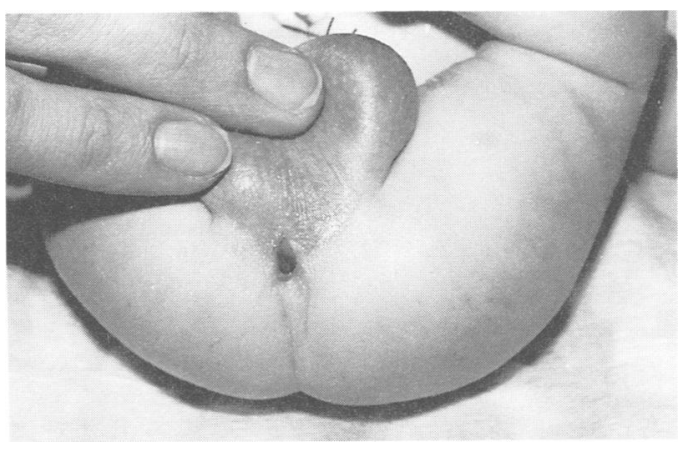

Figure 4 The anus is anteriorly displaced at the posterior limit of the scrotum.

of the cranial bones resulted in what have been called 'large fontanelles' in previously reported cases but was, in our case, virtually agenesis of the largest part of the cranial vault. The probable consanguinity of the parents reinforces evidence for autosomal recessive inheritance in the Baller-Gerold syndrome.

The necropsy findings were non-specific except for moderate polymicrogyria, which has also been mentioned in one of the three necropsy cases reported so far. Abundant extramedullary erythropoiesis, as seen in fetomaternal incompatibility, was present in the liver in one case, but does not provide any explanation for the sudden death which has been recorded in three cases out of 12. The hypertrophy of the islets of Langerhans is also interesting in that it raises the question of a possible hypoglycaemic attack soon after birth. One interesting point stated in the case of Huson et al is the premature separation of the centromeres observed on cytogenetic analysis, pointing to a possible overlap between Baller-Gerold and Roberts SC-phocomelia syndromes. This was not present in our case. However, $\mathrm{C}$ banding, which is the method of choice to express this anomaly, was not performed in our case.

In conclusion, this case report confirms the Baller-Gerold or craniosynostosis-radial aplasia syndrome as a recognisable multiple congenital anomaly syndrome and further delineates the facial appearance and associated malformations. It brings the number of perinatal deaths to four out of 12 , thus suggesting lethality, possibly linked to impairment of glucose homeostasis. Further studies are required, particularly insulin assessment and glucose tolerance tests, to investigate this hypothesis. Prenatal diagnosis rests on echographic detection of cranial and limb malformations during the second trimester.

1 Baller F. Radiusaplasie und Inzucht. Z Menschl Vererbungs Konstit Lehre 1950;29:782-90.

2 Gerold M. Frakturheilung bei einen seltenen Fall kongenitaler Anomalie der oberen Gliedmässen. Zentralbl Chir 1959;84:831-4.

3 Greitzer LJ, Jones KL, Schnall BS, Smith DW. Craniosynostosis-radial aplasia syndrome. $f$ Pediatr 1974; 84:723-4.

4 Cohen MM Jr. Craniosynostosis and syndromes with craniosynostosis: incidence, genetics, penetrance, variability and new syndrome updating. In: O'Donnell JJ, Hall BD, eds. Penetrance and variability in malformation syndromes. New York: Alan R Liss, 1979.

5 Sklower SL, Willer JP, Cohen MM Jr, Feingold M, Desnick RJ. Craniosynostosis-radial aplasia: Baller-Gerold syndrome. Am F Dis Child 1979;133:1279-80. 
6 Woom KC, Kokich VG, Clarren SK, Cohen MM Jr. A morphologic study of affected like-sexed twins. TeratoA my 1980;22:23-35.

7 Anyane-Yeboa K, Gunning L, Bloom AD. Baller-Gerold Anyane-Yeboa $\mathrm{K}$, Gunning $\mathrm{L}$, Bloom $\mathrm{AD}$. Baller-Gerold
syndrome: craniosynostosis-radial aplasia syndrome. Clin Genet 1980;17:161-6.

8 Pelias M, Superneau DW, Thurmon TF. Brief clinical report. A sixth report (eighth case) of craniosynostosisradial aplasia (Baller-Gerold) syndrome. Am $\mathcal{f}$ Med Genet 1981;16:133-9.
9 Huson SM, Rodgers CS, Hall CM, Winter RM. The Baller-Gerold syndrome: phenotypic and cytogenetic Baller-Gerold syndrome: phenotypic and cytogenetic
overlap with Roberts syndrome. $f$ Med Genet 1990;27:371-5.

10 Boudreaux JM, Colon MA, Larusso GD, Parro EA, Pelias MZ. Baller-Gerold syndrome: an 11 th case of craniosyMZ. Baller-Gerold syndrome: an 11 th case of craniosynostosis and radial aplasia. Am f Med Genet 1990;
37:440.

11 Cohen MM Jr. Syndromes with craniosynostosis. In: Cohen MM Jr, ed. Craniosynostosis: diagnosis, evaluation and management. New York: Raven Press 1986:413-590. 